\title{
Mechanical Properties of Tetrafluoro skateboard rubber bearings under nitric and sulphuric acids Condition
}

\author{
GAO Fei ${ }^{1, a}$, SHEN Xiaojun ${ }^{1, a}$, ZHENG Yi $^{2, b}$ and ZHANG Yannian ${ }^{3, c}$ \\ ${ }^{1}$ Chongqing highway engineering quality inspection center, Chongqing, China \\ ${ }^{2}$ Liaoning Institute of Building Materials Inspection, Liaoning, China \\ ${ }^{3}$ School of Civil Engineering, Shenyang Jianzhu University, Liaoning, China \\ a58902855@qq.com, bdandongzy@126.com, donggangzy@126.com
}

\begin{abstract}
Keywords: Tetrafluoro skateboard rubber bearings; nitric and sulphuric acids Condition; compression tests; compressive capacity.

Abstract. The present study was conducted to obtain a better understanding of the variation rule of compressive mechanical properties of tetrafluoro skateboard rubber bearings under nitric and sulphuric acids Condition. A total of 5 specimens were processed in a nitric and sulphuric acids PH4.5, and one specimen was in natural state. The parameter mainly considered time of nitric and sulphuric acids aging processing for specimens. The compressive capacity, ultimate compressive strength and compressive elastic modulus of tetrafluoro skateboard rubber bearings decreased dramatically. The attenuation models conform to reality well which shows that this model is applicable and has vast prospect in assessing the performance of tetrafluoro skateboard rubber bearings under nitric and sulphuric acids condition.
\end{abstract}

\section{Introduction}

In order to study the effect of nitrate sulphuric acid on the mechanical properties of the rubber bearing of the Teflon slide plate of the highway bridge[1-5]. A total of 5 specimens were processed in a nitric and sulphuric acids PH4.5 chamber. After that, five specimens were tested subjected to axial load. The failure modes and mechanical properties are presented and discussed, and the attenuation trends of ultimate compressive strength and compressive elastic modulus of laminated tetrafluoro skateboard rubber bearings under nitric and sulphuric acids aging condition are analyzed. Finally, the attenuation models of ultimate compressive strength and compressive elastic modulus laminated tetrafluoro skateboard rubber bearings are acquired by regressing data of experiment with the least square method.

\section{Experimental Program}

The main goal of the experimental research was to obtain the variation rule of mechanical properties of tetrafluoro skateboard rubber bearings under nitric and sulphuric acids condition.

Fig. 1 shows modes of acid corrosion treatmen of PTFE slide rubber bearings. Different grouping with sodium sulfate treatment of PTFE slide rubber bearings is described in Table 1.

All test specimens were made in Chinese Hengshui Xinli Engineering Inc.

A total of 5 specimens were tested. There were 0,20, 40, 60 and 80 days nitric and sulphuric acids aging processing for specimens. The Dimensions of specimens have no obvious change after aging processing. Change with size of PTFE slide rubber bearings are described in Table 2.

The compression tests were carried out in the Structural Engineering Laboratory of Shenyang Jianzhu University. The compression load was applied by a $5000 \mathrm{kN}$ pressure testing machine.

The specimens were subjected to vertical load, and its loading regimes were described as follows:

(1) The centre of specimens should be adjusted geometrically and physically before preloading. The specimens were loaded to compressive stress $1.0 \mathrm{MPa}$ and displacement sensors were set up.

(2) The specimens were preloaded to permissible compressive stress $[\sigma]$ and keep invariable load 5 minutes. Then, the specimens were unloaded to compressive stress $1.0 \mathrm{MPa}$. 
(3) the tests of compressive elastic modulus: The specimens were increased 1.0MPa every time from compressive stress $1.0 \mathrm{MPa}$ after preloading three times and keep invariable load 3 minutes until the specimens were loaded to $[\sigma]$. Then, the specimens were unloaded to compressive stress $1.0 \mathrm{MPa}$. Loading repeated after 10 minutes, and the loading process continued 3 times.

(4) The tests of ultimate compressive strength: The specimens were increased 1.0MPa every one minute after the tests of compressive elastic modulus until the specimens were loaded to $7[\sigma]$.

Tab.1 Aging Processing of Specimens

\begin{tabular}{|c|c|c|c|}
\hline NO & \multicolumn{3}{|c|}{$\begin{array}{l}\text { days of sulphuric acids } \\
\text { aging processing }\end{array}$} \\
\hline 1 & GJZF4200×300×43ZYBZ01 & & 0 \\
\hline 2 & GJZF4200×300×43ZYXL020 & & 20 \\
\hline 3 & GJZF4200×300×43ZYXL040 & & 40 \\
\hline 4 & GJZF4200×300×43ZYXL060 & & 60 \\
\hline 5 & GJZF4200×300×43ZYXL080 & & 80 \\
\hline 6 & GJZF4200×300×43ZYXL100 & & 100 \\
\hline \multicolumn{4}{|c|}{ Fig.1. Shape of a test specimen } \\
\hline \multicolumn{4}{|c|}{ Tab2.CHANGE WITH SIZE OF PTFE SLIDE RUBBER BEARINGS } \\
\hline $\begin{array}{c}\text { loading } \\
\text { modes }\end{array}$ & $\begin{array}{c}\text { days of } \\
\text { thermal } \\
\text { aging } \\
\text { processing }\end{array}$ & $\begin{array}{c}\text { Dimensions before } \\
\text { sulphuric acids } \\
\text { aging processing } \\
(\mathrm{mm})\end{array}$ & $\begin{array}{c}\text { Dimensions after } \\
\text { sulphuric acids } \\
\text { aging processing } \\
(\mathrm{mm})\end{array}$ \\
\hline \multirow{6}{*}{$\begin{array}{c}\text { Compression } \\
\text { test }\end{array}$} & GJZF4200×300×43ZYBZ01 & $200 \times 301 \times 41$ & - \\
\hline & GJZF4200×300×43ZYXL020 & $202 \times 301 \times 41$ & $202 \times 301 \times 43$ \\
\hline & GJZF4200×300×43ZYXL040 & $200 \times 300 \times 41$ & $199 \times 301 \times 41$ \\
\hline & GJZF4200×300×43ZYXL060 & $201 \times 301 \times 42$ & $200 \times 301 \times 43$ \\
\hline & GJZF4200×300×43ZYXL080 & $199 \times 301 \times 43$ & $199 \times 300 \times 42$ \\
\hline & GJZF4200×300×43ZYXL100 & $200 \times 300 \times 41$ & $201 \times 299 \times 41$ \\
\hline
\end{tabular}

\section{Experimental Results}

Fig. 2 shows failure modes of specimens in compression test. The vertical load increased gradually, specimens were in elastic state when the cracks did not appear. Loading were in a short stagnation when a few fine cracks appeared around agglutinate places of steel plates and rubber of specimens' edge. After that, the vertical displacement increased slowly, but the horizontal displacement increased sharply with load increasing. Meanwhile, protrusions appeared around specimens' edge, and the cracks got larger and deeper fast. The vertical displacement and horizontal displacement increased slowly and load declined precipitously when specimens devastated. The layer-crack damage characteristics of specimens were obvious because steel plates broke away from rubber. The specimens after thermal aging processing were more probably brittle failure than the standard specimen. Moreover, the exposure of steel plate, cracks and other failure phenomena were more serious than the standard specimen. 
The mechanical properties of specimens are shown in table 3. The compressive capacity, ultimate compressive strength and compressive elastic modulus of the specimens decreased obviously with the increasing in time of $\mathrm{d}$ sulphuric acids aging processing.
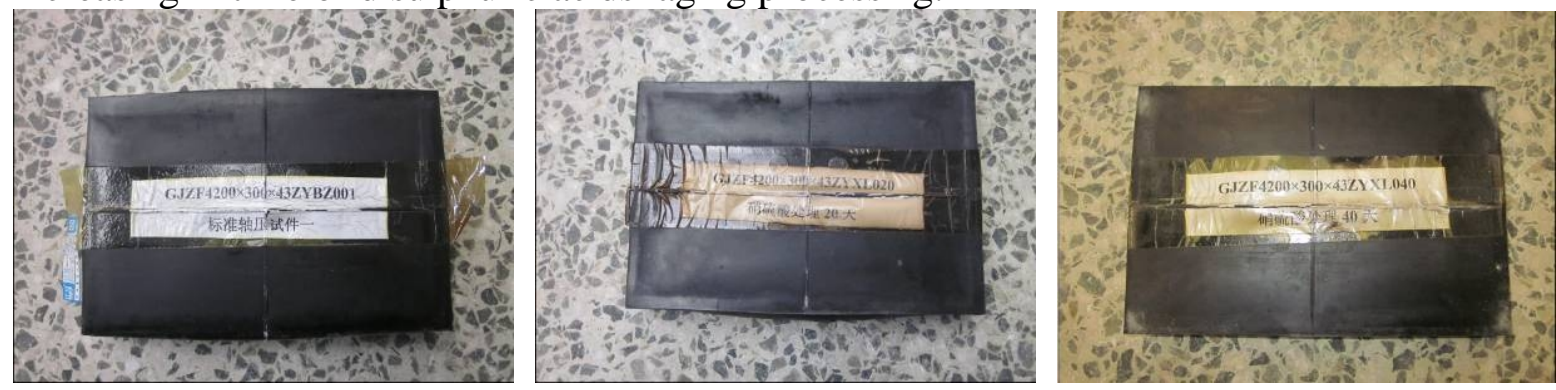

(a) $\mathrm{GJZF}_{4} 200 \times 300 \times 43 Z \mathrm{YBZ} 01$

(b) $\mathrm{GJZF}_{4} 200 \times 300 \times 43 Z \mathrm{YXL} 020$

(c) $\mathrm{GJZF}_{4} 200 \times 300 \times 43 Z Y X L 040$
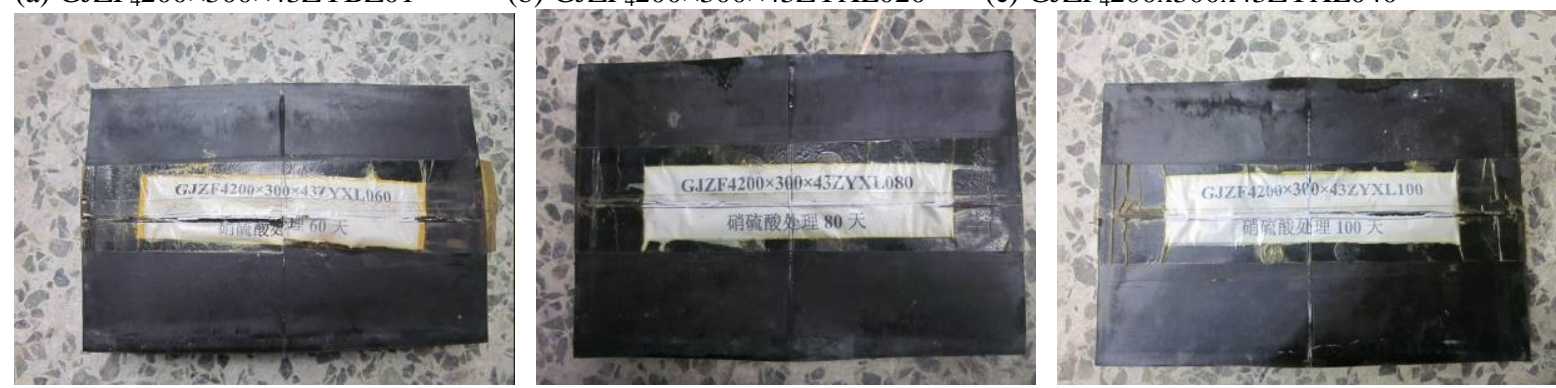

Fig2. Failure modes of specimens

Tab3. COMPARISON OF DIFFERENT SODIUM SULFATE INDEX NUMBER OF PTFE SLIDE RUBBER BEARINGS

\begin{tabular}{|c|c|c|c|c|c|c|c|c|}
\hline \multirow[t]{2}{*}{ Specimen } & \multirow{2}{*}{$\begin{array}{c}\text { Compressiv } \\
\text { e capacity } \\
(\mathrm{kN})\end{array}$} & \multirow{2}{*}{$\begin{array}{l}\text { Ultimate } \\
\text { compressive } \\
\text { strength } \\
(\mathrm{MPa})\end{array}$} & \multicolumn{6}{|c|}{$\begin{array}{l}\text { Displacement corresponding Displacement corresponding } \\
\text { to ultimate compressive } \\
\text { strength }(\mathrm{mm}) \\
\text { to compressive stress } 70 \mathrm{MPa}\end{array}$} \\
\hline & & & vertical & $\begin{array}{l}\text { horizontal } \\
\text { longitudinal }\end{array}$ & $\begin{array}{c}\text { horizonta } \\
1 \text { lateral }\end{array}$ & vertical & $\begin{array}{l}\text { horizontal } \\
\text { longitudinal }\end{array}$ & $\begin{array}{l}\text { horizonta } \\
1 \text { 1 lateral }\end{array}$ \\
\hline $\begin{array}{c}\text { GJZF4200×300 } \times 43 Z \\
\text { YBZ01 }\end{array}$ & 4408.60 & 73.48 & 4.11 & 4.51 & 3.15 & 3.73 & 3.98 & 2.75 \\
\hline $\begin{array}{c}\text { GJZF } 4200 \times 300 \times 43 Z \\
\text { YXL } 020\end{array}$ & 4169.20 & 69.49 & 3.89 & 3.89 & 2.82 & 3.96 & 3.99 & 2.91 \\
\hline $\begin{array}{c}\text { GJZF } 4200 \times 300 \times 43 Z \\
\text { YXL } 040\end{array}$ & 4163.50 & 69.39 & 3.59 & 4.20 & 3.55 & 4.02 & 3.89 & 3.65 \\
\hline $\begin{array}{c}\text { GJZF4 } 200 \times 300 \times 43 Z \\
\text { YXL } 060\end{array}$ & 4160.80 & 69.35 & 3.37 & 4.48 & 4.30 & 3.42 & 4.69 & 4.51 \\
\hline $\begin{array}{c}\text { GJZF4200×300 } \times 43 Z \\
\text { YXL } 080\end{array}$ & 4155.60 & 69.26 & 4.21 & 3.99 & 4.52 & 4.28 & 4.22 & 4.79 \\
\hline $\begin{array}{c}\text { GJZF } 4200 \times 300 \times 43 Z \\
\text { YXL } 100\end{array}$ & 4152.30 & 69.21 & 4.00 & 3.47 & 5.03 & 4.05 & 3.59 & 5.37 \\
\hline
\end{tabular}

\section{Test Analysis}

Fig.3 shows the attenuation curve of compressive capacity of tetrafluoro skateboard rubber bearings under nitric and sulphuric acids. The sulphuric acids aging processing has a significant impact on compressive capacity of 1 tetrafluoro skateboard rubber bearings. The compressive capacity decreased dramatically with the increasing in aging time. 


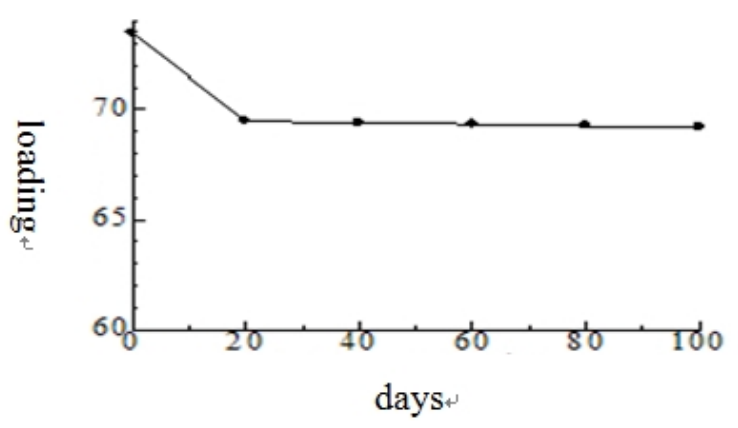

Fig 3. Attenuation curve of ultimate compressive strength

The attenuation model is acquired by regressing data of experiment with the least square method. Fig.4 shows the attenuation curve of ultimate compressive strength of laminated tetrafluoro skateboard rubber bearings. The attenuation function is shown as follows ${ }^{[6-11]}$ :

$$
y=69.547^{-0.001 x}
$$

Where, $y$ is ultimate compressive strength; $x$ is years of nitric and sulphuric acids aging.

The attenuation model of ultimate compressive strength conform to reality well which shows that this model is applicable and has vast prospect in assessing the performance of tetrafluoro skateboard rubber bearings under nitric and sulphuric acids aging condition.

The computational formula of measured vertical stiffness of laminated natural bridge bearings is shown as follows ${ }^{[12]}$ :

$$
K_{\mathrm{v}}^{\mathrm{T}}=\frac{P_{2}-P_{1}}{Y_{2}-Y_{1}}
$$

Where, $\mathrm{P} 1$ is the minimum pressure at third cyclic loading; $\mathrm{P} 2$ is the maximum pressure at third cyclic loading; $\mathrm{Y} 1$ is the minimum displacement at third cyclic loading; $\mathrm{Y} 2$ is the maximum displacement at third cyclic loading.

Fig.7 shows load-vertical stiffness curve of laminated natural bridge bearings. The results show that the damper and thermal aging processing has a relatively little effect on vertical stiffness.

The computational formula of compressive elastic modulus of laminated natural bridge bearings is shown as follows [11]:

$$
E_{1}=\frac{\sigma_{10}-\sigma_{4}}{\varepsilon_{10}-\varepsilon_{4}}
$$

Where, E1 is a calculated value of compressive elastic modulus; $\sigma_{4}$ and $\varepsilon_{4}$ are compressive stress and cumulative compressive strain in the loading stage at $4.0 \mathrm{MPa}$, respectively. $\sigma_{10}$ and $\varepsilon_{10}$ are compressive stress and cumulative compressive strain in the loading stage at $10.0 \mathrm{MPa}$, respectively. The measured compressive elastic modulus of tetrafluoro skateboard rubber bearings is summarized in Table 4.

Tab.4 MEASURED ELASTIC MODULUS COMPARISON OF PTFE SLIDE RUBBER BEARINGS

\begin{tabular}{cc}
\hline Specimen & $\begin{array}{c}\text { Measured compressive elastic modulus } \\
(\mathrm{MPa})\end{array}$ \\
\hline GJZF4200×300×43ZYBZ01 & 1056.15 \\
GJZF4200×300×43ZYXL020 & 847.88 \\
GJZF4200×300×43ZYXL040 & 798.75 \\
GJZF4200×300×43ZYXL060 & 869.58 \\
GJZF4200×300×43ZYXL080 & 811.23 \\
GJZF4200×300×43ZYXL100 & 864.21 \\
\hline
\end{tabular}




\section{Conclusions}

The compression test results show that the specimens after nitric and sulphuric acids aging processing prone to more brittle failure than the standard specimen. Moreover, the steel plate exposed, cracks and other damage phenomena are more serious than the standard specimen.

With the increasing in the aging time and the deepening of the degree of acids aging processing, compressive capacity, ultimate compressive strength and compressive elastic modulus of the tetrafluoro skateboard rubber bearings decreased dramatically.

The test results show that the attenuation trends of ultimate compressive strength and compressive elastic modulus with power function. The attenuation models are acquired by regressing data of experiment with the least square method. The attenuation models conform to reality well which shows that this model is applicable and has vast prospect in assessing the performance of tetrafluoro skateboard rubber bearings under nitric and sulphuric acids aging condition.

\section{Acknowledgements}

This work was financially supported by The national keypoint research and invention program of the thirteenth (2016YFC0700801-05), The Special Fund Project for the Scientific Research of the Quality Control (201210040), Natural Science Foundation Project of Chongqing (CSTC2012jjA0860), Project of Science Research by Chongqing (CSTC2013yykfA30004), Project of Science Research by Shenyang (F12-271-4-00, F12-216-8-00).

\section{References}

[1] Wingard. Use of DSC and DMA to study crystallization as a possible cause for a glove tear. Journal of Thermal Analysis and Calorimetry, 102(2010)469-476.

[2] Y. Zheng, J.Q. Jia, X.J. Shen, et al. Safety evaluation method for laminated rubber bearings of bridge based on extension theory. Journal of south china university of technology (natural science edition), 40, (2012)160-164.

[3] H.T. Chiu, P.A. Tsai and T.C. Cheng. Study of rheological behavior and miscibility of epoxidized natural rubber modified neoprene. Journal of Materials Engineering and Performance, 15(2006)81-87.

[4] S.Z.Xie, D.F.Liu, M.L.Zhou. Rubber Industry Manual (Volume I). Beijing: Chemical Industry Press, 1989. (In Chinese)

[5] D.H. Xu, H.F. Wu, J.F. Wang. The affect of the environmental temperature on the neoprene rubber bearings the shear properties. Highway. 1(2010)76-78. (In Chinese)

[6] I.V. Kalpakidis, M.C. Constantinou. Effects of heating on the behavior of lead-rubber bearings. 1: theory. Journal of Structural Engineering, 135(2009)1440-1449.

[7] I.V. Kalpakidis, M.C. Constantinou. Effects of heating on the behavior of lead-rubber bearings. 2: verification of theory, Journal of Structural Engineering, 135(2009) 1450-1461.

[8] Y.F. Du, J.L. Kou, W.W. Kou. Analysis of thermal mechanical of lam inated rubber bearing under high temperature, Sichuan Building Science. 6(2010)150-153. (In Chinese)

[9] G.S. Cheng. The forecast of the aging characteristics of natural bearings in bridge [J]. World bridges. 40(2010)63-65. (In Chinese)

[10] The industrial standard of communications in the People's Republic of China. Series of elastomeric pad bearings for highway bridges (JT/T 663-2006), 2006. (In Chinese)

[11] The industrial standard of communications in the People's Republic of China. Elastomeric pad bearings for highway bridges (JT/T4-2004), 2004. (In Chinese) 
[12] M.H. Zhou. Service life and application measures of rubber bearings for highway bridges. World bridges. 2(2004)71-74. (In Chinese) 